\title{
Atipical kawasaki disease with coronary aneurysm in infant
}

\author{
Icilio Dodi ${ }^{*}$, Vera Raggi ${ }^{2}$, Marta Verna ${ }^{1}$, Bertrand Tchana ${ }^{1,3}$, Daniela Vignali ${ }^{1}$, Maria Antonietta Bandello , \\ Silvia Lacava ${ }^{2}$, Gian Carlo Izzi ${ }^{1}$ and Aldo Agnetti ${ }^{3}$
}

\begin{abstract}
Kawasaki disease is an acute febrile disease of unknown etiology, characterized by systemic vascular inflammation involving the small and medium sized arteries, with a predilection for the coronary arteries. It represents the leading cause of acquired heart diseases in children in developed countries. Diagnosis, difficult because of the clinical characteristics of the disease with typical signs and symptoms appearing sequentially and not simultaneously, may be even more complicated in case of unusual presentation, leading to delay in recognition, particularly in infant in whom a higher incidence of coronary arteries aneurysms has been reported. A high index of suspicion of Kawasaki disease must be maintained in case of prolonged fever in these patients. Timely appropriate treatment is essential to avoid severe sequels. We report the case of a 2 months old male infant with persistent febrile episode, transferred to us from another institution, who presented on echocardiography giant aneurysms on both coronary arteries.
\end{abstract}

\section{Introduction}

Kawasaki disease is an acute febrile disease of unknown etiology, characterized by systemic vascular inflammation involving the small and medium sized arteries, with a predilection for the coronary arteries, first describe by Tomisaku Kawasaki in Japan in 1967 [1,2]. The disease, counts for the leading cause of acquired cardiac disease in the developed countries, with an annual estimated incidence of 112 cases/100000 children in Japan and 2.9 - 6.9 cases/100000 children in Europe. About 80\% of the children with Kawasaki disease are younger than 5 years of age with the peak of incidence between 6 and 11 months. The disease is rare in neonatal and infant period (only $1.6 \%$ of patients are under 90 days of age) [3] and extremely rare in adolescents and adults. Hospitalization rate of children under 5 years of age in the US was about 20.8/100000 in 2006 and remained constant from 1997 to 2007 [4-6]. The diagnosis relies only on fever associated with transient typical signs and symptoms appearing sequentially, usually not simultaneously present at the time of physical examination, therefore requiring an extremely precise case history.

\footnotetext{
* Correspondence: idodi@ao.pr.it

'Pediatric Hematology and Oncology Unit, Department of Pediatrics, Parma University Hospital, Italy

Full list of author information is available at the end of the article
}

Difficulty in the diagnosis is increased by unusual and incomplete presentation, that may lead to delay in recognition and treatment and therefore severe sequels particularly in infant who are reported to have a higher incidence of coronary aneurysms [7-13]. Prompt and appropriate treatment with intravenous immunoglobulin (IVIG) associated with acetyl salicylic acid significantly reduces the risk of cardiac complications [14-18]. Among the untreated patients 25\% of patients develop cardiac complications, declining to $5 \%$ in the patients who underwent the appropriate treatment 16 . We report on a 2 month old male infant with persistent fever, transferred to us from another institution, who presented giant aneurysms of both coronary arteries on echocardiography.

\section{Case Report}

A 2 month old male infant was referred to our Hospital by another institution where he was admitted one week earlier for a two day history of fever, loss of appetite and rash. At that time laboratory studies showed an elevation of white blood cells (WBC 19.290/mm3). Chest $\mathrm{x}$-ray and abdominal, cerebral and cardiac ultrasound were performed and urine, blood and cerebrospinal fluid (CSF) samples for culture were obtained. All these tests were negative. Therefore a systemic antibiotic therapy 
was started with ampicillin and gentamicin, and after two days switched to ceftriaxone and teicoplanin. Moreover a low dose of IGIV was given. On arrival in our Institution the patient was still febrile. Physical examination showed skin pallor, conjunctivitis and flushed lips, tachycardia, with normal heart sounds, no murmur, tachypnea; an echocardiography was performed, which resulted normal, as well as Chest X-ray, abdominal and cerebral ultrasound. Lumbar puncture was also performed and blood samples were obtained for complete blood cell count and culture. Laboratory studies showed increased WBC $(28.830 / \mathrm{mm} 3)$, platelets $(575000 / \mathrm{mm} 3)$ and Reactive Protein C (RCP $308 \mathrm{mg} / \mathrm{L}$ ) and low hemoglobin $(7.3 \mathrm{~g} / \mathrm{dL})$. The infant underwent red blood cell transfusion and antibiotic therapy with ampicillin and gentamicin was continued. On the second day ankle edema appeared while fever disappeared; blood examination revealed a significant reduction of RCP $(72.4 \mathrm{mg} /$ L) and WBC $(21.910 / \mathrm{mm} 3)$ with platelets persistently increasing $(909000 / \mathrm{mm} 3)$. The child remained well and apyretic for 7 days, then fever recurred, associated with irritability, tachycardia, skin rash on physical examination, and RCP at $239 \mathrm{mg} / \mathrm{L}$ (normal range $0-5$ in our laboratory) and further increase of platelets (1170000/ $\mathrm{mm} 3$ ) on laboratory investigations. The scheduled echocardiography was immediately performed and showed mitral valve insufficiency, pericardial effusion and severe anomalies on both coronary arteries: 3 aneurysms from 5 to $6 \mathrm{~mm}$ in diameter on the right coronary artery; left main coronary, normal proximally, was progressively dilated distally, as well as the circumflex artery, and there was a tubular aneurysm of $5 \mathrm{~mm}$ on the left anterior descending artery. Infusion of IVIG $(2 \mathrm{gr} / \mathrm{Kg}$ in a single dose in twelve hours) and administration of acetyl salicylic acid (100 mg/Kg in 4 doses) was immediately started along with low molecular weight heparin (LMWH). Rapid improvement in clinical status, a significant decrease in RCP and platelet values (RCP $139 \mathrm{mg} /$ L, platelets $882000 / \mathrm{mmc}$ ) with complete normalization 20 days after IVIG infusion was observed. LMWH was then switched to Warfarin. The child was discharged 40 days after admission with acetyl salicylic acid and warfarin therapy, monitored by CoaguCheck System to maintain INR between 2.0 and 2.5. During follow up coronary aneurysms gradually improved. The last cardiac ultrasound showed a $5 \mathrm{~mm}$ left coronary artery aneurysm but right coronary artery was not observable. Mitral valve insufficiency and pericardial effusion were no longer present. A Cardiac catheterization was performed to study the coronary arteries which confirmed the presence of a $5 \mathrm{~mm}$ left coronary artery aneurysm with thrombus, and showed the interruption of the right coronary artery $18 \mathrm{~mm}$ from its origin (Figure 1).

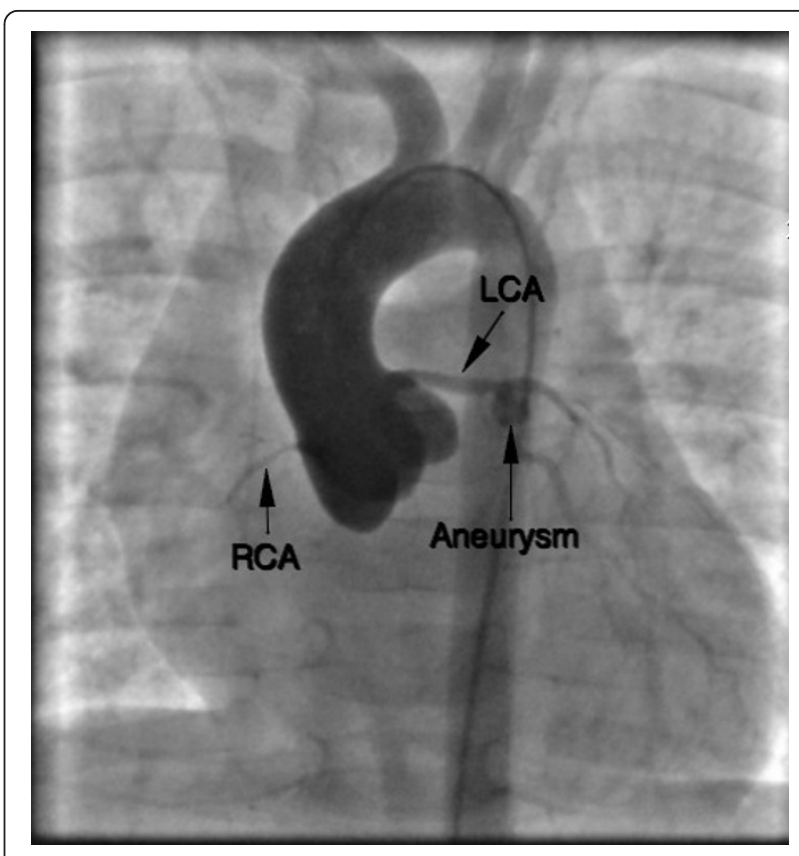

Figure 1 LCA: main left coronary artery dilated with normal distribution and perfusion beyond the aneurysm. Aneurysm: aneurysm of $5 \mathrm{~mm}$ in diameter at the bifurcation of the left coronary artery. RCA: thin right coronary artery, interrupted at 18 $\mathrm{mm}$ from its origin.

Currently the child receives acetyl salicylic acid $5 \mathrm{mg} / \mathrm{Kg}$ and warfarin $0.28 \mathrm{mg} / \mathrm{Kg}$.

\section{Discussion}

Diagnosis of Kawasaki's disease is a demanding challenge because it relies essentially on clinical criteria, with typical signs and symptoms similar to those present in different common children's diseases, appearing sequentially and fleeting. In our case an a posteriori audit of the first week report showed that the patient presented a fleeting episode of palm erythema along with edema of the hands and feet. Erroneous treatment due to mistake in the interpretation of signs and symptoms may alter clinical status and feature without modifying the course of the disease leading to a delay in the diagnosis and the timing of proper therapy. In our case the patient was given a low dose of IVIG which cancelled the fever and improved the clinical status for a week which only transiently slowed down the inflammatory process, leading to significant delay in the diagnosis and severe sequels. The key is a precise and well-done case history, and a close physical examination. Laboratory studies, particularly inflammatory indexes such as RCP may be helpful in the presence of clinical signs. Abnormal platelet count along with clinical signs and RCP value is revealing but is a late index which usually 
appears on the 12th - 14th day of disease whereas treatment should be given between the 6th and the 8th day. In our case abnormal platelet count along with a revision of the history and the other laboratory data should have raised the suspect of Kawasaki disease even in the presence of a completely negative echocardiography with the rapid disappearance of the fever. Unusual presentation is an important risk factor for delay in the diagnosis and severe cardiac sequels. Infants younger than one year of age are at the highest risk for coronary aneurysms and frequently show atypical forms of the disease $[19,20]$. In this category of patients, in case of fever lasting more than three consecutive days, Kawasaki disease should be considered in differential diagnosis.

Delayed diagnosis, along with incomplete clinical manifestation, has been suggested to be the major contributor to the development of coronary artery aneurysms. Timely appropriate treatment is essential for the avoidance of serious sequels in Kawasaki disease, particularly coronary aneurysms, especially in infants younger than one year of age in whom a high index of suspicion of Kawasaki disease must be maintained in case of prolonged fever. The key relies on a precise, detailed and complete case history and careful clinical evaluation and monitoring.

\section{Consent}

Written informed consent was obtained from the patient for publication of this case report and accompanying images. A copy of the written consent is available for review by the Editor-in-Chief of this journal.

\section{Author details \\ ${ }^{1}$ Pediatric Hematology and Oncology Unit, Department of Pediatrics, Parma University Hospital, Italy. ${ }^{2}$ School of Specialization in Pediatrics, School of Medicine, University of Parma, Italy. ${ }^{3}$ Pediatric Cardiology Unit, Department of Pediatrics, Parma University Hospital, Italy.}

\section{Authors' contributions}

ID: prepared the manuscript and search the literature

VR: Collected the data, participate in the search of literature

MV: participate in the collection of the data

BT: made the diagnosis, made the echocardiography, review the manuscript DV: participate in the collection of the data

MAB: made the diagnosis, participate in the preparation of the manuscript

SL: participated in the collection of the data

Gl: review the manuscript

AA: made the cardiac catheterization

All authors read and approved the final manuscript.

\section{Competing interests}

The authors declare that they have no competing interests.

Received: 27 October 2010 Accepted: 17 April 2011

Published: 17 April 2011

\section{References}

1. Kawasaki T: Acute febrile mucocutaneous syndrome with lymphoid involvement with specific desquamation of the fingers and toes in children. Arerugi 1967, 16:178-222.

2. Kawasaki T, Kosak F, Okawa S, Shigematsu I, Yanagawa H: A new infantile acute febrile mucocutaneous lymph node syndrome prevailing in Japan. Pediatrics 1974, 54:271-276.

3. Bhatt M, Anil SR, Sivakumar K, Kumar K: Neonatal Kawasaki disease. Indian J Pediatr 2004, 71:353-354.

4. Yanagawa H, Nakamura Y, Yashiro M, Oki I, Hirata S, Zhang T, Kawasaki T: Incidence survey of Kawasaki disease in 1997 and 1998 in Japan. Pediatrics 2001, 107:E33.

5. Falcini F, Cimaz R, Calabri GB, Picco P, Martini G, Marazzi MG, Simonini G, Zulian F: Kawasaki's disease in northern Italy: a multicenter retrospective study of 250 patients. Clin Exp Rheumatol 2002, 20:421-426.

6. Holman RC, Belay ED, Christensen KY, Folkema AM, Steiner CA, Schonberger LB: Hospitalizations for Kawasaki syndrome among children in the United States, 1997-2007. Pediatr Infect Dis J 2010.

7. Burns JC, Wiggins JW Jr, Toews WH, Newburger JW, Leung DY, Wilson H, Glodé MP: Clinical spectrum of Kawasaki disease in infants younger than 6 months of age. J Pediatr 1986, 109:759-763.

8. Rosenfeld EA, Corydon KE, Shulman ST: Kawasaki disease in infants less than one year of age. J Pediatr 1995, 126:524-529.

9. Anderson MS, Todd JK, Glode MP: Delayed diagnosis of Kawasaki syndrome: an analysis of the problem. Pediatrics 2005, 115(4)

10. Belay ED, Maddox RA, Holman RC, Curns AT, Ballah K, Schonberger LB: Kawasaki syndrome and risk factors for coronary artery abnormalities: United States, 1994-2003. Pediatr Infect Dis J 2006, 25(3):245-249.

11. Genizi J, Miron D, Spiegel R, Fink D, Horowitz Y: Kawasaki disease in very young infants: high prevalence of atypical presentation and coronary arteritis. Clin Pediatr (Phila) 2003, 42(3):263-267.

12. Rosenfeld EA, Corydon KE, Shulman ST: Kawasaki disease in infants less than one year of age. J Pediatr 1995, 126:524-529.

13. Witt MT, Minich LL, Bohnsack JF, Young PC: Kawasaki disease: more patients are being diagnosed who do not meet American Heart Association criteria. Pediatrics 1999, 104(1):e10.

14. Newburger JW, Takahashi M, Burns JC, Beiser AS, Chung KJ, Duffy CE, Glode MP, Mason WH, Reddy V, Sanders SP, Shulman ST, Wiggins WJ, Hicks RV, Fulton DR, Lewis AB, Leung DYM, Colton T, Rosen FS, Melish ME: The treatment of Kawasaki syndrome with intravenous $\mathrm{G}$ globulin. $N$ Engl J Med 1986, 315:341-7.

15. Kato H, Sugimura T, Akagi $T$, Sato $N$, Hashino K, Maeno $Y$, Kazue T, Eto G, Yamakawa R: Long-term consequences of Kawasaki disease. A 10-to 21year follow-up study of 594 patients. Circulation 1996, 94:1379-1385.

16. Fong NC, Hui YW, Li CK, Chiu MC: Evaluation of the efficacy of treatment of Kawasaki disease before day 5 of illness. Pediatr Cardiol 2004, 25:31-34.

17. Takahashi M, Mason W, Lewis AB: Regression of coronary aneurysms in patients with Kawasaki syndrome. Circulation 1987, 75:387-394.

18. Newburger JW, Takahashi M, Gerber MA, Gewitz MH, Tani LY, Burns JC, Shulman ST, Bolger AF, Ferrieri P, Baltimore RS, Wilson WR, Baddour LM, Levison ME, Pallasch TJ, Falace DA, Taubert KA: Diagnosis, treatment, and longterm management of Kawasaki disease: a statement for health professionals from the Committee on Rheumatic Fever, Endocarditis, and Kawasaki Disease, Council on Cardiovascular Disease in the Young, American Heart Association. Pediatrics 2004, 114:1708-1733.

19. Yeo Y, Kim T, Ha K, Jang G, Lee J, Lee K, Son C, Lee J: Incomplete Kawasak disease in patients younger than 1 year of age: a possible inherent risk factor. Eur J Pediatr 2009, 168(2):157-62, Erratum in: Eur J Pediatr. 2010 Mar;169(3):377.

20. Pannaraj PS, Turner CL, Bastian JF, Burns JC: Failure to diagnose Kawasaki disease at the extremes of the pediatric age range. Pediatr Infect Dis $J$ 2004, 23:789-791.

doi:10.1186/1824-7288-37-19

Cite this article as: Dodi et al:: Atipical kawasaki disease with coronary aneurysm in infant. Italian Journal of Pediatrics 2011 37:19. 